\title{
Disjoint Reference in Modern Standard Arabic
}

\author{
Islam M. Al-Momani \\ Department of English Language and Literature, Princess Alia University College \\ Al-Balqa' Applied University, Amman, Jordan \\ E-mail: almomani_islam@yahoo.com
}

Received: 20-12- 2014

Published: 01-07- 2015
Accepted: 26-02- 2015

doi:10.7575/aiac.ijalel.v.4n.4p.256
Advance Access Published: February 2015

URL: http://dx.doi.org/10.7575/aiac.ijalel.v.4n.4p.256

\begin{abstract}
The paper aims at providing an explanation of pronominals in Modern Standard Arabic (hereafter MSA) by assuming that the relation between pronouns and available binders is constrained by the same syntactic condition, i.e., a pronoun cannot be coindexed with a c-commanding NP within its local domain. It also aims at providing a unified account of two types of pronominals in MSA, referential and bound pronouns. These two types of pronouns have different values for their binders; where a referential pronoun requires a name to be coindexed with; a bound pronoun requires a distinct subject, i.e., a quantifier as its binder. The paper adopts Principle B of the theory of binding to account for these pronouns by examining how this principle can express the content of disjoint reference for pronouns embedded in Ss, NPs and PPs in MSA and to see whether the phenomenon of disjoint reference in Arabic supports principle (B).
\end{abstract}

Keywords: Arabic, principle (B), pronominals, reflexives, coindexation, local domain, government

\section{Introduction}

The theory of binding has been the focus of a wide array of an extensive scholarly literature since the emergence of Generative Syntax. Within this approach, binding constraints on coreference are usually defined in syntactic terms and considerable efforts in the last three decades have been directed at attempting to define the constraints on corefernce within and across sentences. This theory makes another prediction by claiming that anaphors and pronominal are in complementary distribution, for instance, in English, reciprocals and reflexives fall into the category of anaphors; whereas, personal pronouns fall into the category of pronominals. It assumes that anaphors and pronominals must be in complementary distribution since anaphors must be locally A-bound (principle A), whereas pronominals must be locally A-free (principle B). In order to explain that reflexives and pronouns in English must be in complementary distribution, consider the following examples:

$$
\begin{aligned}
& \text { 1. a. John }{ }_{\mathrm{i}} \text { blamed himself }_{\mathrm{i}} / \text { him }_{*_{\mathrm{i}}} \\
& \text { b. John } \\
& \mathrm{i} \text { thinks that Bill blamed himself }{ }_{*_{\mathrm{i}}} / \operatorname{him}_{\mathrm{i}} \text {. }
\end{aligned}
$$

The grammatical property which has been modeled syntactically based on the structural position of the pronoun's (reflexive or non-reflexive) referent holds in relation to the pronoun itself. Thus, the binding theory concerns itself with "co-indexation relation" (the relation of bearing the same index between any two nominal expressions occupying argument positions in a sentence), and seeks to express the constraints on this relation. The binding theory plays a crucial role in syntactic theory; its constraints are designed to predict that the referential domains of reflexives and pronouns are nonoverlapping, i.e., are in complementary distribution. In English, for instance, the pronoun him and the reflexive himself, as shown in (1) above, are nearly in complementary distribution, i.e., their referential domains are nearly completely nonoverlapping. This observation plays a central role to formulate structural conditions that form the base of current theories of 'binding' (for an overview, see Chomsky 1981, 1986, 1995, Lasnik 1989, Safir 2004).

However, the following sentence raises a question: are reflexives and pronominals in English in complementary distribution?

\section{2. $\mathrm{John}_{\mathrm{i}}$ stung the rope around himself $\mathrm{i}_{\mathrm{i}} / \mathrm{him}_{\mathrm{i}}$}

Here, the reflexive pronoun himself and the personal pronoun him in (2) are members of different classes of NPs that the binding theory does not handle (this will be the center point when we discuss binding and PPs).

The majority of the literature of anaphora (the three basic principles of the theory of binding) argues that the term 'anaphor' as opposed to 'pronominal' is an assumption that the lexical item is in some way referentially dependent on an antecedent; whereas, a pronominal is not. In the syntactic literature, the identity of dependency is based on a structural, syntactic relationship. According to Safir (2004:185), a form is pronominal if "it consists only of a bundle of grammatical features with no idiosyncratic lexical or semantic content..."; anaphors on the other hand completely lack inherent semantic content. 
The distribution of anaphora has been the central issue in the syntactic literature as done by Chomsky (1981, 1986, 1995), Chomsky and Lasnik (1993), Pollard and Sag (1994), Reinhart and Reuland (1993), and Safir (2004) while discussing English anaphora.

Anaphoric distribution, in the different versions of the standard binding theory, is based on some type of some command relationship as the C-command within Chomskyan syntax (this paper adopts this condition while analyzing pronominals in Arabic) or the O-command in Head Driven Phrase Structure Grammar (HPSG) of Pollard and Sag (1994).

The basic idea in HPSG is that NPs of different sorts obey different hierarchical conditions on their interpretation according to their position on the SUBCAT(egorization) list of a given predicate. This hierarchical condition is stated in terms of local $\mathrm{O}$ (bliqueness)-command:

3. Let $\mathrm{Y}$ and $\mathrm{Z}$ be synsem objects with distinct LOCAL values, $\mathrm{Y}$ referential.

Then $\mathrm{Y}$ locally o-commands $\mathrm{Z}$ just in case $\mathrm{Y}$ is less oblique than $\mathrm{Z}$.

(Pollard and Sag 1994: 253)

The definition in(3) states that one synsem object $\mathrm{Y}$ locally o-commands another $\mathrm{Z}$ just in case they are both on the same SUBCAT list and Y is less oblique than $\mathrm{Z}$.

Based on their definition of local o-command, Pollard and Sag's definition of local o- binding is as the following:

4. $\mathrm{Y}$ (locally) o-binds $\mathrm{Z}$ just in case $\mathrm{Y}$ and $\mathrm{Z}$ are coindexed and $\mathrm{Y}$ (locally) o-commands $Z$. If $Z$ is not (locally) o-bound, then it is said to be (locally) o-free.

(Pollard and Sag 1994:254)

\section{Objectives and Methodology}

The theory of binding has claimed to formulate and systematize fundamental principles which characterize and constrain the relations of anaphors and pronouns to possible antecedents. Arabic has a complicated system of pronominal usage, with numerous pronominal variants and pronominally used forms that are determined by the social roles and the role-relationships of speech participants, which in turn are governed by social and cultural factors such as the context of discourse, formality, age and sex. Thus, the main objective of this study, therefore, is to evaluate critically Principle B of the binding theory with pronominal constructions possible mainly in Arabic.

In order to pursuing the objectives of this paper to a consistent end, the researcher follows a complex system of methodology. The historical-descriptive approach has been applied to get hold of a historical background and record a descriptive analysis of the theory of binding and its development in the generative linguistic domain of anaphora. The comparative approach has, also, been used to analyze Arabic pronouns and compare them to those in English to present the functional similarities between pronouns in both languages. Finally, the researcher follows the analytical approach to analyze all the MSA data. The data used here are an amalgamation of genuine sentences uttered by native speakers of Arabic. Authentic grammar books are also used as sources; furthermore, a few Arab grammarians and professors of Arabic language are referred to for their consultation and testing the validity of the data.

\section{Hypothesis}

The paper is designed to analyze "pronominals in Arabic" in the light of Principle B of the Binding Theory (BT). In order to weigh up the explanatory and satisfactoriness of this principle, this paper aims at checking whether "pronominals in MSA" are satisfying Principle B of BT or not, i.e., can they be explained and accounted properly under this existing theory or cannot?

The following symbols are used to represent certain Arabic sounds that don't match IPA symbols.

/T/ voiceless alveo-dental emphatic stop

/d̂ / voiced alveo-dental emphatic stop

/ṣ/ voiceless alveolar emphatic fricative

$/ \mathrm{h} /$ voiceless pharyngeal fricative

/ $/$ voiced pharyngeal fricative

/q/ voiceless uvular stop

$/ \dot{\mathrm{g}} /$ voiced velar fricative

$/ \mathrm{x} /$ voiceless velar fricative

\section{Discussion}

\subsection{General Over-viewing of Chomsky's Theory of Binding}

The theory of binding first presented by Chomsky (1981) based on Reinhart's (1976) C-Command analysis. The theory of binding, according to Chomsky (1981), is composed of three principles: Principle A deals with pure anaphors like the reflexive pronoun 'himself' as in (1a). Principle B deals with pronominals like the personal pronoun 'him' as in (1b). Principle $\mathrm{C}$ deals with R-expressions like full noun phrases or proper names. Chomsky defines principles A and B in 
terms of two notions: C-Command and Governing Category (see (13) and (12a and b) below). C-command is a notion of syntactic prominence that corresponds to the structural relation that holds between an operator and a variable in logic; whereas, governing category is a notion of locality which corresponds to the minimal domain containing a predicate and all its arguments, including the subject. Principle A states that an anaphor must be coreferential with a ccommanding noun phrase in its governing category; while, principle B states that a pronominal must not be coreferential with any c-commanding noun phrase in its governing category.

Chomsky (1981) argues that nominal expressions are classified into four types based on the two valued features [anaphoric] and [pronominal]. The theory of binding organizes the four categories as follows:

5. Types of NPs

[+ anaphoric, - pronominal $\quad$ anaphors.

[- anaphoric, + pronominal] pronominals.

[- anaphoric, - pronominal] R-expressions.

[+ anaphoric, + pronominal] PRO.

These four types of NPs are exemplified as in the following sentences:

6. a. Anaphor: Bill saw himself in the mirror.

b. Pronominal: Bill saw him.

c. R-expression: Bill saw John.

d. PRO: John wants [PRO to leave].

(6a, b, and c) exemplify three types of overt nominals; whereas, (6d) exemplifies the binding of a hypothesized null anaphor PRO. The distribution and analysis of the first three types of NPs are handled by the Binding theory, while the relation of PRO (the unexpressed subject of non-finite clauses) to its antecedent falls under the theory of Control. Consider (7) and (8) where the former illustrates obligatory control and the latter optional control:

7. The teacher asked his student $\mathrm{i}_{\mathrm{i} R \mathrm{P}}$ to leave the classroom]

8. $\mathrm{John}_{\mathrm{i}}$ thinks that $\left[\mathrm{PRO}_{\mathrm{i} / \mathrm{j}}\right.$ to win the game $]$ is not easy.

In (7), the unexpressed subject of the non-finite clause is his student, while in (8), the null subject can correspond either to John or anybody else.

The range of anaphoric relations among nominal phrases in sentences is regulated by the principles of the theory of binding. That is, for each type of overt nominal expressions, a binding requirement specifies the domain within which a nominal can or cannot have an antecedent. In a somewhat simplified description of the standard formulation of this theory (Chomsky 1981, 1986; Chomsky and Lasnik 1993), it consists of the following principles:

9. Binding theory (BT):

Principle A: An anaphor must be bound in a local domain.

Principle B: A pronominal must be free in a local domain.

Principle C: An R-expression is free.

Anaphors and pronominals can be referentially dependent on another NP, namely, their antecedents.

An anaphor picks its reference from the subject NP "antecedent" within the same sentence

In sentence (10), for instance, the subject NP John on which the reflexive pronoun himself is dependent for its interpretation is the antecedent. We indicate that the anaphor and its antecedent have the same referent by means of coindexation.

10. John $_{\mathrm{i}}$ shot himself $\mathrm{i}$

The interpretation of pronouns, which is the main concern of this paper, differs from that of reflexives. The pronoun him in sentence (11) must refer to an entity different from the subject NP John, while the reflexive pronoun in the same position in sentence (10) must refer to an entity denoted by John. Whereas the reflexive must be bound, the pronoun must be free.

11. *John ${ }_{\mathrm{i}}$ shot him ${ }_{\mathrm{i}}$.

(The asterisk in sentence (11) refers to the ungrammaticality of the particular coindexation). 
Since the theory of binding is developed within the theory of government, it makes use of the fundamental notions: "govern" and "governing category" in order to decide the local domain of pronominals and reflexives. The tow notions are characterized by Chomsky as in (12a and b).

12. a. $\alpha$ govern $\beta$ iff:
i. $\alpha=\mathrm{X}$
ii. $\alpha$ c-commands $\beta$
iii. $\beta$ is not protected by a maximal projection.

(Chomsky1981:163)

b. $\alpha$ is the governing category for $\beta$ iff $\alpha$ is the minimal category containing $\beta$ a governor of $\beta$, where $\alpha=\mathrm{NP}$ or S.

(Chomsky 1981:188)

In (12a), $\alpha(=\mathrm{X})$ represents a lexical category, i.e., N, V, A, or P. Maximal projections are: CP, IP, VP, AP, NP, and PP. The word "protected" in condition (iii) of (12a) is understood in the following way: $\beta$ is protected by a maximal projection if the latter includes $\beta$ but not $\alpha$.

In the general case "government" is the relation between a lexical head and its complement. So, the heads verbal, nominal, prepositional, and adjectival constructions govern the elements they are subcategorized for. Moreover, INFL or (AGR in INFL) governs the subject of a tensed clause. The subject of an embedded infinitival construction is governed by the complementizer "for" in the comp. position, or by a matrix verb which has the property of inducing $\mathrm{S}$ (ubject) deletion in its complement, if either of these is present, if neither is present the subject of an embedded infinitive is ungoverned. Moreover, the notion of $\mathrm{C}$ (constituent) Command hereafter: C- Command Condition established by Reinhart $(1976,81,83)$ plays a crucial role in Chomsky's theory of binding. She states her definition as follows:

13. "Node A c-commands node B if neither A nor B dominates the other and the first branching node which dominates A dominates B."

(Reinhart (1976: 32))

So, $\mathrm{X}$ is considered to be bound by $\mathrm{Y}$ if $\mathrm{X}$ is c-commanded by $\mathrm{Y}$ and co-indexed with it. But $\mathrm{X}$ is considered to be free if it's not co-indexed with $Y$ as shown in (10) and (11) above.

Additionally, an interpretive procedure is needed to interpret coindexed NPs as coreferential and noncoindexed NPs as non-coreferential (see Chomsky and Lasnik 1993; Chomsky 1995). To unify the indexing procedure and the interpretive procedure, Chomsky and Lasnik (1993) restate the binding principles as interpretive procedures, dispensing with the indexing procedure. Their formulation is as in (14).

14. Interpretive binding theory:

Condition A: If $\alpha$ is an anaphor, interpret it as coreferential with a c-commanding phrase in D.

Condition B: If $\alpha$ is a pronoun, interpret it as disjoint from every c-commanding phrase in D.

Condition C: If $\alpha$ is an R-expression, interpret it as disjoint from every c-commanding phrase.

This version is as version (9) requires the concept of local domain. The difference between the interpretive version in (14) and the standard version in (9) is that under the latter, binding principles are conditions on representations; whereas, under the former, the binding principles are interpretive procedures that assign certain interpretive relations among phrases and are, by nature, derivational.( this paper adopts the definition in (9). Another assumption has to do with the way the BT applies to chains formed by Movement and Copy (Chomsky 1995). This is a version of the Chain Uniformity Condition (CUC) (see Chomsky 1995, Brass 1986, and Freiden and Vergnaud 2001).

A question that arises at this point: At what point of syntactic derivation do the principles of BT apply?

Under Principles and Parameters, the BT is satisfied at a single level of representation, i.e., the level of S-structure (Chomsky 1981, Brass 1986, among others). Under minimalist assumptions, the levels of D-structure and S-structure are eliminated, therefore, analyses relying on these levels are not viable. Thus, under Chomsky's minimalist program, BT is claimed to apply at LF exclusively (see Chomsky 1991, 1992, 1993, 1994, and 1995).

\subsection{Disjoint Reference in Arabic}

\subsubsection{Pronouns in Verbal Object Positions}

Like English, in Arabic, the overt pronoun system contains lexical anaphors and pronominals that can be distinguished from each other precisely in the way that they may select their antecedents. Chomsky (1995) assumes that an anaphor (reflexive pronouns) must have a c-commanding antecedent within its governing category, which is handled by 
principle A of the theory of binding, pronominals (non-reflexive pronouns), on the other hand, can be classified as referential pronouns which are handled by principle B of the same theory.

In a verbal object position, Arabic reflexive and non-reflexive pronouns exhibit complementary distribution. Thus, in the following sentences, where the reflexive pronoun nafs (self) can be bound by an antecedent in its governing category, i.e., 'IP', the pronoun $h u$ must be free in that governing category.

\section{5. a. Zaid- $\mathrm{un}_{\mathrm{i}}$ ? intaqada nafsahu $\mathrm{u}_{\mathrm{i}}$ \\ Zaid-nom criticized himself \\ 'Zaid criticized himself.' \\ b.*Zaid-un ? $_{\text {intaqada-hu }}$ \\ Zaid-nom criticized-him \\ 'Zaid criticized him.'}

The data in (15) exhibit complementarity that refers to the fact that in direct object position in Arabic, the reflexive pronoun nahsahu, himself can only be interpreted as having the same semantic value as its clause-mate antecedent, Zaidun; whereas, the non-reflexive pronoun hu, him can only be interpreted as finding its reference outside the sentence; the antecedent of $h u$ can never be the subject NP Zaidun. Once a pronoun is separated from its antecedent by a clause boundary, the sentence becomes grammatical as in (16).

$$
\begin{aligned}
& \text { 16. }{ }_{\mathrm{IP}}\left[\text { Zaid-un }_{\mathrm{i}} \mathrm{ya}^{\mathrm{c}} \text { taqidu }_{\mathrm{CP}}\left[\text { ?anna }{ }_{\mathrm{IP}}\left[\text { Hind-an tuhibu-hu } \mathrm{i}_{\mathrm{i}}\right]\right]\right. \\
& { }_{\text {IP }} \text { [Zaid-nom thinks }{ }_{\mathrm{CP}}\left[\text { that }{ }_{\mathrm{IP}}[\text { Hind-acc loves-him }]\right] \\
& \text { 'Zaid thinks that Hind loves him.' }
\end{aligned}
$$

However, a reflexive pronoun in the same position of the pronoun in (16) will lead to the ungrammaticality of the sentence as in (17).

$$
\begin{aligned}
& \text { 17. }{ }_{\mathrm{IP}}^{*}\left[\text { Zaid-un } \mathrm{y}_{\mathrm{i}} \mathrm{ya}^{\mathrm{c}} \text { taqidu }{ }_{\mathrm{CP}}\left[\text { ?anna }{ }_{\mathrm{IP}}[\text { Hind-an tuhibu nafsahu } \mathrm{i}]\right]\right] \\
& { }_{\mathrm{IP}}\left[\text { Zaid-nom thinks }{ }_{\mathrm{CP}}\left[\text { that }{ }_{\mathrm{IP}}[\text { Hind-acc loves himself }]\right]\right] \\
& \text { 'Zaid thinks that Hind loves himself.' }
\end{aligned}
$$

Based on the aforementioned examples, I claim that among the imaginable anaphoric relations in the direct object position in Arabic, some are necessary, some are possible, and still others are prohibited, depending on the nature of NPs involved and the syntactic configurations in which they occur. Consider the following examples:

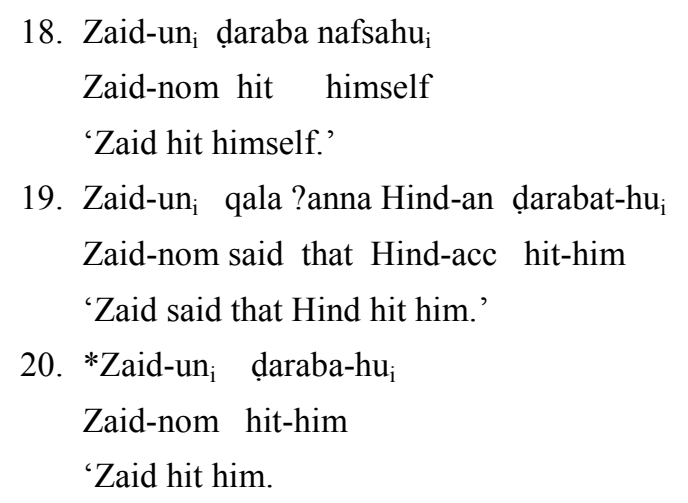

In (18), the reflexive pronoun nafsahu (himself) allows only the reading in which 'nafsahu' must refer to Zaidun. hu in (19) can be referentially dependent upon Zaidun. In contrast, (20), has no reading in which the pronoun 'hu' refers to Zaidun.

Hence, the syntactic properties for reflexive binding in MSA are handled by the binding Principle A. In contrast with anaphoric expressions, pronominals impose no positive binding requirement on their antecedent, but instead, a negative one, which requires that a pronominal does not have an antecedent that is too adjacent to it. Note that in (15a) where coreference is a must between the reflexive pronoun nafsahu and the subject NP Zaidun within the governing category (IP), there is a clause boundary between the pronoun $h u$ and its antecedent in (16).

The complementary distribution between anaphors and pronominals is argued to be based on structural properties of the sentence and the position in which the pronoun whether reflexive or non-reflexive occurs. These basic structural principles that guide the appearance of reflexive and non-reflexive pronouns are argued by Safir (2004:9) as in (21). 
21. a. Principle A: An anaphor (reflexive pronoun) must be bound in Domain D (some locally defined domain).

b. Principle B: A pronoun (non-reflexive pronoun) must be free in Domain D (some locally defined domain).

Safir (2004:9) defines binding as follows:

22. Binding: $\mathrm{X}$ binds $\mathrm{Y}$ if $\mathrm{X} \mathrm{c}$-commands $\mathrm{Y}$ and $\mathrm{X}$ and $\mathrm{Y}$ are coindexed. If $\mathrm{X}$ is not bound it is free.

The structural notion of c-command is defined also by Safir (2004:9) as follows:

23. C-command: $\mathrm{X}$ c-commands $\mathrm{Y}$ if the first branching node dominating $\mathrm{X}$ also dominates $\mathrm{Y}$.

In order to illustrate these principles, consider the following tree diagram in (24) that represents the examples in (15):

24.

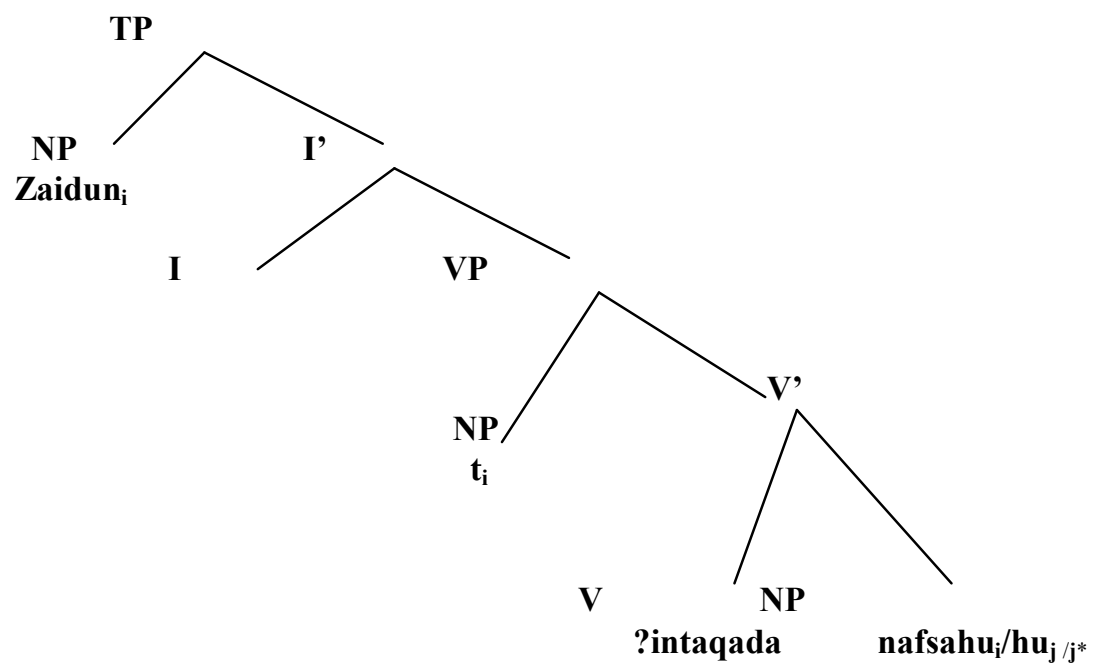

Chomsky (1995:102), while describing binding relations in examples as in (15), states "Under the hypothesis that subjects are base-generated internal to VP, the VP will be the GC (Governing Category, the 'local domain'), with the trace of the subject (which has itself moved to the [Spec, IP]) serving as the binder". Accordingly, The VP in the representation above is the minimal domain because it is the first branching node that dominates the NP, $t$ and also dominates the NP object node containing nafsahu or $h u$. The [Spec, IP] which is the NP, containing the trace, t, ccommands the object NP position. In this case, if the reflexive pronoun nafsahu is coindexed with the trace, $t$ of Zaidun, the trace binds the reflexive pronoun; whereas, if the non-reflexive pronoun $h u$ is coindexed with the trace of Zaidun, then the trace binds the non-reflexive pronoun. This leads to the ungrammaticality of the sentence because it violates Principle B which states that non-reflexive pronouns must be free in the local domain (VP). The only grammatical use of the non-reflexive pronoun as in (15b) is to be coindexed with an antecedent outside the VP or in the discourse. Therefore, Principle B of the binding theory in Chomsky (1995) argues that a pronominal is free in its governing category (local domain). This predicts the position in a sentence in which a pronoun must be disjoint in reference from a c-commanding NP in its governing category.

Now, let us consider the behavior of pronouns in "Ss" in MSA containing only a single clause and witness how principle B works in Arabic. The following sentence illustrates cores of disjoint reference.

$$
\begin{aligned}
& \text { 25. } *{\text { Zaid- } \mathrm{un}_{\mathrm{i}} \text { ra?a-hu }}_{\mathrm{i}} \\
& \text { Zaid-nom saw-him } \\
& \text { Zaid saw him. }
\end{aligned}
$$

In (25), hu, (him) cannot be locally bound and thus cannot be coindexed with the subject of the sentence Zaidun in its governing category.

Thus, a restriction which characterizes the interpretation of pronominals in Arabic is captured by Principle B of the theory of binding. This principle accounts for the impossibility of the pronoun $h u$ in sentence (25), for instance, to be coindexed with a c-commanding NP in its governing category.

\subsubsection{Pronouns in NP Positions}

In the examples presented thus far, the VP has served as the relevant domain for binding, i.e. Domain D. Thus, Principle $\mathrm{B}$ of the theory of binding gives correct results at the level of IP, "S". It also gives correct results at the level of "NP" which is considered according to the theory of binding as another local domain. Consider the examples in (26) where "him" is interpreted as proximate to John. 
26. a. $\mathrm{John}_{\mathrm{i}}$ saw $\left[\mathrm{NP}\right.$ my picture of him ${ }_{\mathrm{i}}$ ]

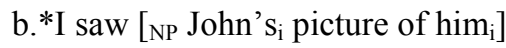

c. $\mathrm{John}_{\mathrm{i}}$ thought I saw [NP a picture of himi

Principle B makes correct predictions about (a), (b), and (c) of (26). Sentences (26a and c) are grammatical because the pronoun him is free in its local domain, the NP. Sentence (26b) is ungrammatical because the pronoun is bound and coindexed with John in the local domain violating principle B. The same is true of their Arabic equivalents as in (27).

$$
\begin{aligned}
& \text { 27. a. Zaid- } \mathrm{un}_{\mathrm{i}} \text { ra?a [NP șuwar-i la-hu }{ }_{\mathrm{i}} \text { ] } \\
& \text { Zaid-nom saw [NP pictures-my of-him] } \\
& \text { 'Zaid saw my pictures of him.' } \\
& \text { b. *Omar-un ra?a [NP șuwara Zaid-in }{ }_{\mathrm{i}} \mathrm{la}_{\mathrm{a}} \mathrm{hu}_{\mathrm{i}} \text { ] } \\
& \text { Hind-nom saw [NP pictures Zaid-gen of-him] } \\
& \text { 'Hind saw Zaid's pictures of him.' }
\end{aligned}
$$

Chomsky (1995) analyzes other examples in which the local domain for condition A and B is the NP as shown in (28).

28. John likes [NP Bill's $\mathrm{s}_{\mathrm{i}}$ stories about himself $\mathrm{h}_{\mathrm{i}} / \mathrm{him}_{*_{\mathrm{i}}}$ ]

In (28), the local domain of the reflexive pronoun himself and the non-reflexive pronoun him is the NP Bill's stories about himself/him. The reflexive pronoun cannot refer to an antecedent outside the NP because Bill inside the NP is a potential; whereas, the non-reflexive pronoun is free within the NP and refers to an antecedent outside the NP.

In Arabic, the local domain for condition A and B can also be the NP as proposed in Chomsky's analysis (1995). Consider the following example:
29. Zaidun yuhibu [NP qișașa Mohammad-in ${ }_{\mathrm{i}}{ }^{\mathrm{c}} \mathrm{an}^{\mathrm{h}} \mathrm{hu}_{*_{\mathrm{i}}} /$ nafsihi $\left._{\mathrm{i}}\right]$
Zaid-nom likes [NP stories Mohammad-gen about-him/himself]
'Zaid likes Ali’s stories about him/himself.'

In (29), the local domain of the reflexive pronoun nafsihi and the non-reflexive pronoun $h u$ is the NP qișașa

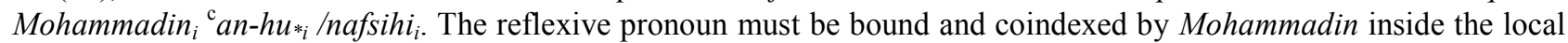
domain, NP; whereas, the non-reflexive pronoun cannot refer to an antecedent inside the NP because it must be free in that local domain. It could refer either to Zaidun the subject NP of the sentence or to an antecedent in the discourse.

However, in some cases a reflexive pronoun resides within an NP of similar syntactic structure with no local binder as in (30).

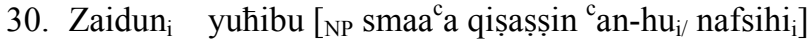
Zaid-nom likes [NP hearing stories about-him/himself]
'Zaid likes hearing stories about him/himself.'

In (30), the non-reflexive pronoun $h u$ is free within its local domain, the NP, whereas, the reflexive pronoun nafsihi cannot find its antecedent in the NP as in (30), but must find it in the in the specifier of the VP as exactly the case in English as in (31).

\section{1. $\mathrm{John}_{\mathrm{i}}$ likes [NP stories about himself $\mathrm{i}_{\mathrm{i}}$}

The example in (31) shows that the definition of the binding domain must be flexible enough to allow for varying structures to serve as a relevant domain. Chomsky (1995:102) reduces the notion 'Governing Category' (local domain) to that of 'Complex Functional Complex' (CFC) so as to incorporate this distinction and generalize the local domain from NP to VP by arguing that a CFC is "a projection containing all grammatical functions compatible with its head". The rule for finding the appropriate domain for binding according to him is as follows: 
32. The Governing Category (the local domain) for $\alpha$ is the minimal CFC that contains $\alpha$ and a governor of $\alpha$ and in which $\alpha$ 's binding condition could, in principle, be satisfied.

(Chomsky 1995:102)

Therefore, for instance, a CFC for a verb includes all of its arguments (including the subject); a CFC for a noun is the head noun and all its arguments. Note that the absence of a potential binder plays an important role for Principle B of the theory of binding. In other words, there must be no potential binder for a pronominal within CFC in order for the $\mathrm{CFC}$ to be the governing category (local domain) for a pronominal.

In (28), the CFC is the NP, Bill's stories about himself/him in which the non-reflexive pronoun must be free satisfying Principle B. Since the determiner position is filled with Bill, Bill serves as a binder for the reflexive pronoun himself. In (31), the NP lacks the filled D position; the NP alone does not include a governor and thus, the CFC must be the VP, the domain in which John, the binder, binds the reflexive pronoun.

It has been argued by different linguists as mentioned earlier in this paper that Principles A and B predict complementary distribution of anaphors and pronominals as shown in (33) and (34).
33. a. $\left[\mathrm{CFC}_{2} \mathrm{John}_{\mathrm{j}}\right.$ said [that $\left[\mathrm{CFC1}\right.$ Mary $_{\mathrm{i}}$ loves herself $\mathrm{i}_{\mathrm{ij}}$. $\left.]\right]$
b. [CFC2 John $_{\mathrm{j}}$ said [that $\left[\mathrm{CFC1}\right.$ Mary $_{\mathrm{i}}$ loves him $_{\mathrm{i} * j}$. $\left.]\right]$

34. a. [CFC2 $\mathrm{John}_{\mathrm{i}}$ said[that[CFCl himself ${ }_{\mathrm{i}}{ }^{\text {is intelligent. }]]}$

b. [CFC2 $\operatorname{John}_{\mathrm{i}}$ said[that[CFC1 he $_{\mathrm{i}}$ is intelligent.]]

However, counter examples of this generalization may appear as illustrated in (35).
35. a. [ CFC2 The men $_{\mathrm{i}}$ like $\left[\mathrm{CFC1}\right.$ each other' $\mathrm{s}_{\mathrm{i}}$ cars.]
b. [CFC2 The men $_{\mathrm{i}}$ like $\left[\mathrm{CFC}_{1}\right.$ their $\mathrm{r}_{\mathrm{i}}$ cars.]

Apparently, the anaphor each other in (35a) and the pronominal their in (35b) are not in complementary distribution. According to the theory of binding of Chomsky (1995), the governing category of the anaphor each other in (35a) is $\mathrm{CFC}$, which is the minimal CFC containing a potential binder 'the men'. On the other hand, the governing category for the pronominal their in (35b) is CFC1, since CFC1 is the minimal CFC where the binding Principle could be satisfied. Thus, the pronominal 'their' is free in CFC1.

Now, we will consider the occurrence of possessive pronouns in the specific position of NPs. In English, this position does not present a problem for Principle B of the binding theory. Consider (36).

36. John is reading [NP his book].

The CFC for the pronoun his is the NP and hence, Principle B correctly predicts that this pronoun is free within it. However, the possessive pronoun can be co-indexed with the subject NP John outside its governing category.

Now, let us consider the behavior of possessive pronouns in Arabic sentences in accordance with Principle B by examining the following sentences:

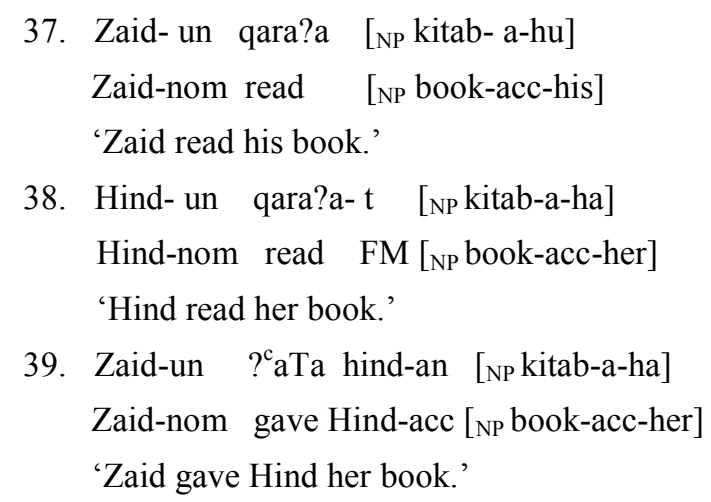

Sentences (37) and (38) present a similarity to the English sentence (36). In (37) and

(38), the pronouns $h u$ and $h a$ are co-indexed with the subject NPs Zaidun and Hindun. Since Zaidun and Hindun ccommand $h u$ and $h a$ outside their governing category, (NP), and coindexation between them is possible. However, in (39) though the pronoun $h a$ cannot be co-indexed with the subject NP Zaidun as in (37) and (38), the pronoun can be co-indexed only with the indirect object NP Hindun.

Principle (B) gives correct results for (37), (38), and (39). The crucial difference

between (37) and (38) in one hand and (39) on the other hand seems to be that in 
the former, the antecedent of the pronouns is the subject, while in the latter, the antecedent of the pronoun is the indirect object. Thus, pronouns in Arabic are not bound by a c-commanding antecedent within their local domain that contains a pronoun and a governor of that pronoun.

\subsubsection{Pronouns in Prepositional Phrases}

Now, let us consider the behavior of pronouns in prepositional phrases in Arabic and see how principle B of the theory of binding works in Arabic. Consider the following sentence where Principle B correctly predicts that the pronoun $h i$ is free in its local domain:

$$
\begin{aligned}
& \text { 40. }{ }^{*} \text { ' }^{\mathrm{arraft}-\mathrm{u} \quad \text { Zaid- }_{\mathrm{an}}{ }_{\mathrm{i}}{ }^{\mathrm{c}} \text { alai-hi }} \mathrm{i}_{\mathrm{i}} \\
& \text { introduced(I) Zaid-acc to-him } \\
& \text { 'I introduced Zaid to him.' }
\end{aligned}
$$

The pronoun hi, (him) in the oblique phrase cannot be bound by the direct object in its governing category since it violates Principle B.

The same principle also predicts the interpretation of resumptive pronouns in Arabic. Consider the following example in which the pronoun $h u$ cannot be referentially dependent upon Zaidun.

$$
\begin{aligned}
& \text { 41. r-rajul- } \mathrm{u}_{\mathrm{i}} \text { ?allathi } \text { ? }^{\mathrm{c}} \text { ata Zaid-un la-hu } \mathrm{i}_{\mathrm{i}} \text { l-kitab-a hadara } \\
& \text { the-man who gave Zaid-nom for-him the-book came } \\
& \text { 'The man who Zaid gave the book to him came.' }
\end{aligned}
$$

In (41), the resumptive pronoun ?allathi, (who) cannot refer the subject NP, Zaidun because the pronoun $h u$ would be bound within its governing category. Thus, the resumptive pronoun is coindexed with the head NP r-rajulu which is outside the governing category of the pronoun $h u$.

However, the standard binding theory does not always give a correct prediction about the distribution of pronominals in prepositional phrases in Arabic. Consider the following sentences:
Zaid-nom gave the-book to-him
'Zaid gave the book to him.'
42. ${ }^{*}$ Zaid- $^{-u_{i}}$ ? $^{\mathrm{c}}$ ta l-kitaba la-hu
43. a. Zaidun ${ }_{i}$ wada a $^{c}$ l-kitaba bijanibi-hi
Zaid-nom put the-book next to-him
'Zaid put the book next to him.'
b. Zaidun ${ }_{\mathrm{i}}$ ?iltafata hawla-hu $\mathrm{i}_{\mathrm{i}}$
Zaid-un looked around-him
'Zaid looked around him.'
c. $Z^{2}$ aidun $_{i}$ bahatha ' an l-mafatihi xalfa-hu
Zaid-nom looked for the-keys behind-him
'Zaid looked for the keys behind him.'
d. Zaidun ${ }_{i}$ ?ajlasa Hind-an bi-janib-hi $i_{i}$
Zaid-nom made sit Hind-acc next to-him
'Zaid made Hind sit next to him.'
e. Zaidun dafa ${ }^{c} a$ l-binta ba $^{c}$ idan ${ }^{c}$ an-hu
Zaid-nom pushed the-girl away from-him
'Zaid pushed the girl away from him.'
f. - Zaid-un ?axada Hind-an ?ila bait-i-ha.
Zaid Nom took Hind-acc to home-gen-her
'Zaid took Hind to her home.'

In sentences (42 and 43), we can assume that the subject NP Zaidun is base-generated in the VP. Thus, the spec. of the VP in each sentence is Zaidun. Zaidun in sentence (42) does not binds the pronoun $h u$, and thus, free in its local domain, the IP with no violation of Principle B. However, in the examples in (43), Zaidun binds the pronoun in PP If the VP is considered the local domain for binding. According to Principle B, the pronoun must be free within its local domain, thus the examples in (43) should be ungrammatical with the reading that the pronoun and the subject NP are coreferent. Thus, there is a violation of Principle B. 
The failure of the standard binding theory to handle such examples leads us to adopt Tenny's analysis (2003:1). She assumes that the pronoun in prepositional phrases is a "short distance" pronoun. Accordingly, the examples in (43) suggest that the local domain for binding when the short distance pronoun resides in a PP should not be the VP, but rather a more restricted local domain such as the PP itself.

In fact, this analysis is proposed in works done by Hestvik (1991), Reinhart and Reuland (1993), Safir (2004), and Büring (2005). According to them, if the PP forms its own domain, the short distance pronoun as in (43) would not be bound within the local domain and hence, all the examples in (43) would not be in violation of Principle B.

According to Hestvik's analysis, the PP is considered as a Complete Functional Complex (CFC) that serves as a local domain. The PP is considered as the minimal domain which includes the pronoun and its governor as seen in the examples in (43). However, the minimal domain which includes the pronoun, its governor and a subject is the IP. Based on this analysis, the pronoun $h i$, (him) in sentence (43a), for instance, is coindexed with the subject NP of the IP, but it is not necessarily bound by it, i.e., they share the same referent, but their semantic value are filled independently. Thus, the pronoun based on this characterization of the CFC, may be free even if it is coindexed with the subject of the sentence with no violation of Principle B. Thus, the pronoun $h i$ in (43a) is free of a local binder in the PP, but it is not free in the IP because the PP is adjoined within it and hence, the pronoun is licensed.

\subsubsection{Referential and Bound Pronouns}

This section sheds light upon two types of pronominals in Arabic, referential pronouns that can be coindexed with a name and bound pronouns that can be coindexed with quantifiers. Of course both types of pronouns are coindexed with an antecedent outside their governing categories. Consider sentences (44) and (45) illustrating referential and bound pronouns respectively.

$$
\begin{aligned}
& \text { 44. ya }{ }^{c} \text { taqidu Zaid- } \mathrm{un}_{\mathrm{i}} \text { ?anna l-mu } \mathrm{u}^{\mathrm{c}} \text { allim-a yuhibbu-hu } \mathrm{u}_{\mathrm{i}} \text { kathiran } \\
& \text { thinks Zaid-nom that the-teacher-acc loves-him much } \\
& \text { 'Zaid thinks that the teacher loves him very much. }
\end{aligned}
$$

45. Kulluwahid-in $\mathrm{i}_{\mathrm{i}} \mathrm{y}^{\mathrm{c}}$ taqidu ?anna l-mu ${ }^{\mathrm{c}}$ allim-a yuhibbu-hu $\mathrm{i}_{\mathrm{i}}$ kathiran everyone-gen thinks that the-teacher-acc loves-him much

'Everyone thinks that the teacher loves him very much.'

Like referential pronouns, bound pronouns have to obey Principle B. Thus, the following sentences are unacceptable with the pronoun ' $h u$ ' coindexed with the quantifiers kulluwahidin, (everyone) in (46) and man, (who) in (47) within their governing categories, violating Principle B of the theory of binding.

$$
\begin{aligned}
& \text { 46. *kulluwahid-in } \text { yuhibbu-hu }_{\mathrm{i}} \\
& \text { everyone-gen loves-him } \\
& \text { 'Everyone loves him.' } \\
& \text { 47. * } \text { man }_{\mathrm{i}} \text { yuhibbu-hu }{ }_{\mathrm{i}} \text { ? } \\
& \text { who loves-him } \\
& \text { 'Who loves him?' }
\end{aligned}
$$

The derivations that involve movement of a quantificational phrase (including wh-element) over a coindexed pronominal have long been an area of inquiry. May (1977) argues that Quantificational Phrases (QPs) such as everyone, someone, and wh-elements, etc. should move in LF (logical form) via Quantifier Raising (QR) to a position consistent with their scope. Consider sentence (48) with its semantic representation in (49).

48. Bill loves everyone.

49. For every X, X a person, Bill likes X.

After the application of (QR), sentence (50) below is produced as the LF representation associated with (48) and (49).

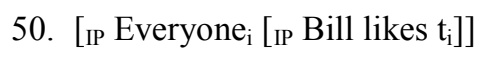

In (50), the quantifier 'everyone' adjoins to IP $(=\mathrm{S})$, leaving a trace, $t$ in its base position. The scope of everyone, i.e., the original sentence can be defined as its 'c-command domain.' Accordingly, the trace, $t$ is coindexed with everyone, and since movement took place, this coindexation can be considered as the relation between the quantifier and the variable that it binds.

Chomsky (1982) proposes that if a sentence, at the level of LF, contains a quantifier, this quantifier must have a scope and that scope must include a variable. This would demand the raising of the quantifiers kulluwahidin in (46) and man in (47) as shown by illustrating their LF representations in (51) and (52) respectively. 
51. *[ IP2 kulluwahidin ${ }_{\mathrm{i}}\left[\mathrm{IP1} \mathrm{t}_{\mathrm{i}}\right.$ yuhibbu-hu $\mathrm{i}_{\mathrm{i}]}$

52. *[CP $\operatorname{man}_{\mathrm{i}}\left[\mathrm{IP}_{\mathrm{i}} \mathrm{t}_{\mathrm{i}}\right.$ yuhibbu-hu ${ }_{\mathrm{i}}$ ?] $]$

Sentences (51) and (52) are ungrammatical because the pronoun $h u$ is not only A-bound by the trace in the subject position but also A'-bound by the moved quantifiers. The ungrammaticality of these sentences can be accounted for if we assume that Principle B holds at LF. In (51) and (52), the pronoun $h u$ is bound by a variable, namely, the trace in its governing category; therefore, coreferential interpretation is not permitted.

Referential pronouns and bound pronouns can occur in embedded clauses as shown in (53), (54), and (55) respectively.

53. Zaid-un $_{\mathrm{i}}$ qala ?anna-hu $\mathrm{i}_{\mathrm{i}}$ laa yuhibbu Hind-an

Zaid-non said that-he NEG love Hind-acc

'Zaid said that he does not love Hind.'

54. kulluwahid-in ${ }_{i}$ qala ?anna-hu $u_{i}$ laa yuhibbu Hind-an

everyone-gen said that-he NEG love Hind-acc

'Everyone said that he does not love Hind.'

55. $\operatorname{man}_{\mathrm{i}}$ qala ?anna-hu $\mathrm{i}_{\mathrm{i}}$ laa yutibbu Hind-an

who said that-he NEG love Hind-acc

'Who said that he does not love Hind.'

The LF representations of (54), and (55) are as in (56), and (57):

56. [IP kulluwahidin $n_{i}$ [IP2 $_{\mathrm{i}} \mathrm{t}_{\mathrm{i}}$ qala [IP1 ?anna-hu $_{\mathrm{i}}$ laa yuhibbu Hindan]]]

57. [CP $\operatorname{man}_{\mathrm{i}}\left[\mathrm{IP2}_{2} \mathrm{t}_{\mathrm{i}}\right.$ qala [IP1 ?anna-hu $\mathrm{i}_{\mathrm{i}}$ laa yuhibbu Hindan]]]

It has generally been assumed that every quantificational phrase must undergo either overt or covert movement to an operator position to bind its trace at the LF level (cf. Postal 1971, Wasow 1972, May 1977, Koopman and Spotiche 1982, Chomsky 1986 and 1992, among others). In sentence (53), the local domain, i.e., the governing category for the pronoun $h u$ is the embedded clause, which contains the pronoun and its governor. Thus, (53) is grammatical because the pronoun is free in that domain. The LF representations in (56), and (57) show that the pronoun $h u$ in (54), and (55) is A'- bound by the quantifiers kulluwahidin and man and A-bound by the variable, i.e., the trace in a higher clause, which is outside its local domain, i.e., the innermost clause. This bound pronoun is free in its governing category and thus, (54), and (55) are grammatical sentences. In (56), the quantifier is assumed to move covertly, yielding its LF representation, whereas in (57), the quantificational phrase man undergoes overt movement.

The aforementioned examples discussed so far show that referential as well as bound pronouns can occur in either the subject or object position of embedded clauses.

Our analysis of referential and bound pronouns crucially relies on the notion of c-command. This analysis is called a structural analysis. Consider the following configurations where the trace of a quantificational phrase precedes and ccommands the coindexed pronoun:

58. $\operatorname{man}_{\mathrm{i}}$ faqada mafatiћa-hu

who lost keys-his

'Who lost his keys.'

59. kulluwahid-in ${ }_{i}$ ya $^{c}$ taqidu ?anna-hu fa? $_{i}$ ?zun

everyone-gen thinks that-he winner

'Everyone thinks that he is the winner.'

The LF representations of (58) and (59) are as in (60) and (61).

60. [CP who $_{\mathrm{i}}[\mathrm{IP} \mathrm{t}$ lost keys-his $\mathrm{i}$ ]

61. [IP kulluwahidin [IP $_{\text {t }}$ ya ${ }^{\mathrm{c}}$ taqidu ?anna-hu $_{\mathrm{i}}$ fa?izun]]

In both: (60) and (61), the trace of a quantificational phrase c-commands the coindexed pronominal. Thus, as assumed by Chomsky (1986a), Lasnik and Stowell (1991) and many others that either overtly or covertly raised wh-phrases as in (57) and (60) appear in [Spec, CP], whereas, LF raised quantifiers taking clausal scope are adjoined to IP.

A pronoun in the subject position of a more deeply embedded clause can be referentially dependent upon a quantified antecedent in the matrix subject position. Consider sentence (62) and its LF representation in (63). 
62. kulluwahid-in ya $^{c}$ taqidu ?anna-ka qulta ?anna-hu $u_{i}$ yajibu ?an yugadir

everyone-gen thinks that-(you) said that-he must to leave

'Everyone thinks that you said that he must leave.'

63. [IP kulluwahidin ${ }_{\mathrm{i}}$ [IP1 $\mathrm{t}_{\mathrm{i}} \mathrm{ya}^{\mathrm{c}}$ taqidu [IP2 ?anna-ka qulta [IP3 ?anna-hu $_{\mathrm{i}}$ yajibu ?an yugadir]]]]

These facts suggest that both referential pronouns and bound pronouns are subject to Principle B of the theory of binding.

\section{Conclusion}

The paper has discussed pronominals in MSA in accordance with Principle B of the theory of binding. Pronominals in Arabic crucially rely on the structural notion of the 'c-command' and are all subject to Principle B, i.e., free in their local domain, but differ in their binding domain. The standard binding theory gives correct prediction about the distribution of pronominals in IPs and NPs, but fails to always give a correct prediction about the distribution of pronominals in prepositional phrases in Arabic. This failure leads us to adopt Tenny's analysis (2003), where she assumes that the pronoun in prepositional phrases is a "short distance" pronoun. Accordingly, the local domain for binding when the short distance pronoun resides in a PP should not be the VP, but rather a more restricted local domain such as the PP itself. For a bound pronoun, the binding domain must contain a distinct subject (a quantifier) to be coindexed with; whereas, a referential pronoun could be coindexed with a name in its binding domain.

\section{Reference}

Brass, A. (1986). Chain and Anaphoric Dependency. Ph.D dissertation, MIT. Büring, D. (2005). Binding Theory. Cambridge:Cambridge University Press. http://dx.doi.org/10.1017/CBO9780511802669

Chomsky, N. (1977). On Wh-Movement. Formal Syntax, eds. By P.W. Culicover, T. Wasow and A. Akmajian. New York: Academic Press, pp. 71-132.

Chomsky, N. (1981). Lectures on Government and Binding. Dordrecht: Foris.

Chomsky, N. (1982). Some Concepts and Consequences of the Theory of Government and Binding. Cambridge, MA.: MIT Press.

Chomsky, N. (1986a). Knowledge of Language: Its Nature, Origin and Use. New York: Praeger.

Chomsky, N. (1986b). Barriers. Cambridge, MA.: The MIT Press.

Chomsky, N. (1989). Some Notes on Economy and Derivation and Representation. MIT Working papers in Linguistics $10,43-74$.

Chomsky, N. (1992). A Minimalist Program for Linguistic Theory. MIT Occasional Papers in Linguistics 1

Chomsky, N. (1993). A Minimalist Program for Linguistic Theory. In The View from Building 20, eds. K. Hale and S. J. Keyser, 1-49. Cambridge, Mass.: MIT Press.

Chomsky, N (1994). Bare Phrase Structure. MIT Occasional Papers in Linguistics, volume 5. Cambridge, Mass.: MIT Department of Linguistics and Philosophy.

Chomsky, N. (1995). The Minimalist Program. Cambridge, Mass.: MIT Press.

Chomsky, N. and Lasnik, H. (1993). The Theory of Principles and Parameters. Syntax: An International Handbook of Contemporary Research. J. Jacobs, A. Von Stechow, W. Sternefeld and T. Vennemann. Berlin, Walter de Gruyter.

Freiden, R. and Vergnaud, J. R. (2001). Exquisite Connections: Some Remarks on the Evolution of Linguistic Theory. Lingua, 111, 639-665. http://dx.doi.org/10.1016/S0024-3841(01)00045-6

Hestvik, A. (1991). Subjectless Binding Domains. Natural Language and Linguistic Theory 9 (3): $455-496$. http://dx.doi.org/10.1007/BF00135355

Hestvik, A. (1992). LF Movement of Pronouns and Antisubject Orientation. Linguistic Inquiry 23: 557-594

Koopman, H. and Sportiche, D. (1982). Variables and the Bijection Principle. The Linguistic Review 2, $139-160$. http://dx.doi.org/10.1515/tlir.1982.2.2.139

Lasnik, H. (1989). On the Necessity of Binding Conditions. In H. Lasnik, ed., Essays on Anaphora, Kluwer, Dordrecht. pp. 149-167. http://dx.doi.org/10.1007/978-94-009-2542-7_9

Lasnik, H. and Stowell, T. (1991). Weakest Crossover. Linguistic Inquiry 22, 687-720.

May, R. (1977). The Grammar of Quantification. Ph.D. dissertation, MIT, Cambridge, Massachusetts.

Pollard, C. and Sag, I. (1994).Head-Driven Phrase Structure Grammar. University of Chicago Press, Chicago.

Postal, P.M. (1971). Cross-Over Phenomena. Holt, Reinhart and Winston, New York.

Reinhart, T. (1976). The Syntactic Domain of Anaphora. MIT, Ph.D dissertation.

Reinhart, T. (1983). Anaphora and Semantic Interpretation. Beckenham: Croom Helm Ltd.

Reinhart, T. and Reuland, E. (1993). Reflexivity. Linguistic Inquiry 24, 657-720.

Safir, K. (2004). The Syntax of Anaphora. New York: Oxford University Press.

http://dx.doi.org/10.1093/acprof:oso/9780195166132.001.0001

Tenny, C. (2003). Short Distance Pronouns, Argument Structure, and the Grammar of Sentence. Manuscript, Carnegie Mellon University.

Wasow, T. (1972). Anaphoric Relations in English. Ph.D dissertation, MIT. 